\title{
External Liquid Dosage Form
}

National Cancer Institute

\section{Source}

National Cancer Institute. External Liquid Dosage Form. NCI Thesaurus. Code C69060.

Liquid, usually multidose preparation consisting of a liquid active substance per se, intended for cutaneous use. 